\title{
Application of the experimental design technique in fuel dose adjustment of common rail injector
}

The article presents a simplified methodology for testing Denso common rail electromagnetic injectors, which was based on an adjustment of idling fuel dosage. In order to determine the parameters significantly affecting this process, the design of experiments technique (DoE) was applied. Due to the non-linear course of the rates characteristics obtained on the diagnostic test bench, the trivalent fractional plan was used. Analysis of computational data has shown that the generated parabolic model is well suited to the actual measurement results, as the injector dosage is slightly out of projected values. The calculations were carried out in the STATISTICA computer program, which takes into account the specificity of the experimental theory methods and is one of the most universal tools available on the market. Innovation is the effective implementation of the proposed methodology in the repair process, which has not been taken into account in this regard yet.

Key words: common rail injector, design of experiments technique, fuel dose adjustment, idling

\section{Introduction}

One of the most common malfunctions in common rail injectors is the deterioration of the cooperation between the control needle and the spray nozzle [7]. It may be the result of normal or accelerated use of the precision pair. In the first case, the fault usually becomes apparent after a longer period of engine operation [9]. However, pathological wear takes place in a much shorter time, usually due to insufficient lubrication [21], overheating of the contact zones [1] and chemical influence of combustion products [8]. Since the discussed parts are in direct contact with the fuel supplied, the decisive factor is its quality [14], physicochemical properties and the presence of solid [17] and chemical contaminants [3]. The friction wear of the precision pair affects the injector dosage processing an unfavourable way as it results in an increased flow of return flows, i.e. the amount of fuel reaching the overflow. As a result, idling and low load operation becomes uneven. After disassembling the injector, the fault can be detected at the low operating pressure on the diagnostic test bench. However, in the other areas of work, the correct values of fuel injection rates are observed because the lift of the control needle is not hindered and it overcomes the resistance of the needle spring without any obstacles. In such situations, the test procedure can be simplified by eliminating the aforementioned malfunction by adjusting the idle dose.

Denso electromagnetic injectors are characterized by their construction and operating principle, similar to Bosch products of the first generation [11]. For this reason, their regulation is carried out in the same way. Unfortunately, until now the manufacturer has not released a comprehensive repair technology, so the impact of construction parameters on the value of individual rates remains difficult to estimate [12]. With regard to the idling speed, the change of the factory settings is obtained by replacing the needle and/or calibration shims. Reducing the thickness of the first one changes the preload of the lower spring, which stops the height of the control needle and consequently the amount of fuel injected. In turn, the second one, located between the electromagnet coil and the main body, affects the overall injector dosage (Fig. 1). Therefore, the increase in its thickness may be carried out to a limited extent [13].

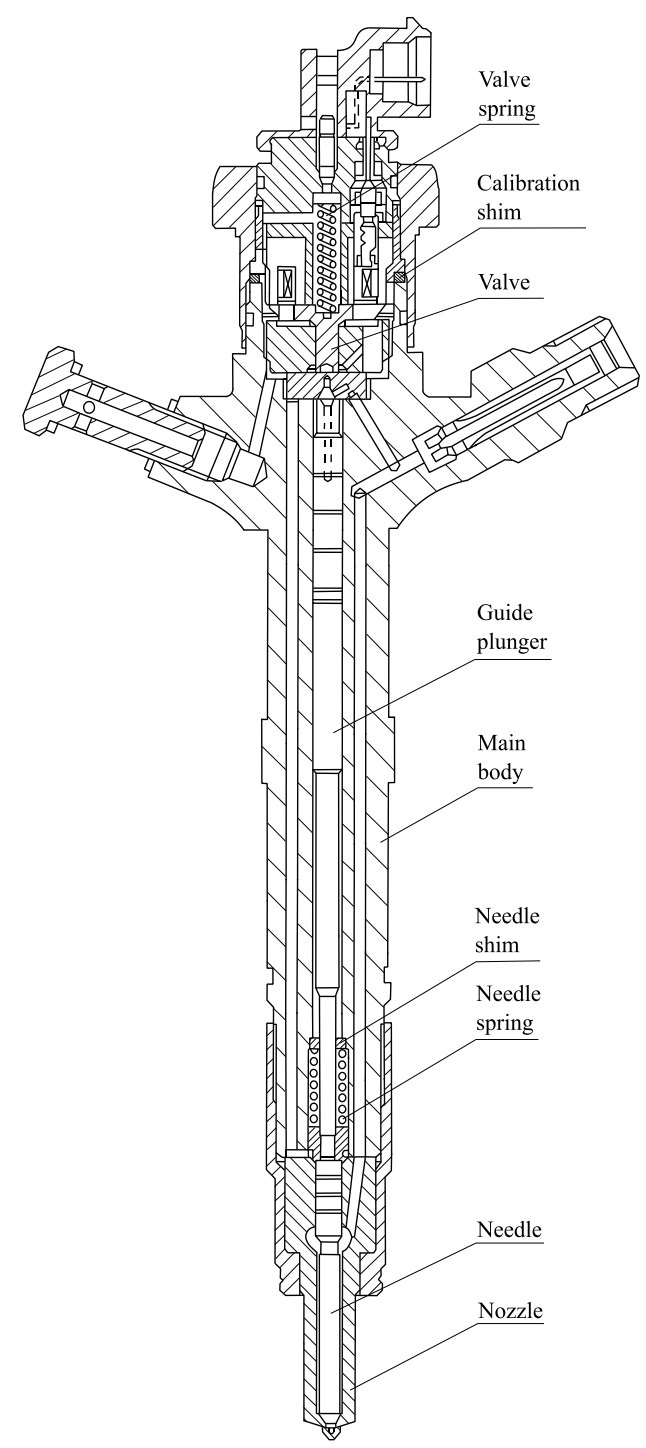

Fig. 1. Denso injector construction 
In order to determine the parameters that have a significant impact on the idling rate, the design of experiments technique was used, which in this respect has not been taken into account until now. The application of this methodology allowed to solve the problem of unambiguous determination of the dimensions of regulatory shims, and thus their precise selection out of specific selection groups. As a result, the testing process of Denso electromagnetic injectors on diagnostic test benches has been simplified.

\section{Methods}

\subsection{Test object and test beds}

The test object was a Denso electromagnetic injector, dismounted from a 2.2 HDI (High pressure Direct Injection) engine of a Citroën Jumper II delivery van with an operational mileage of 156 thousand $\mathrm{km}$. It is a fourcylinder, 16-valve drive unit with direct fuel injection in the common rail system.

The research was carried out according to the adopted own methodology, including two stages of implementation (Fig. 2).

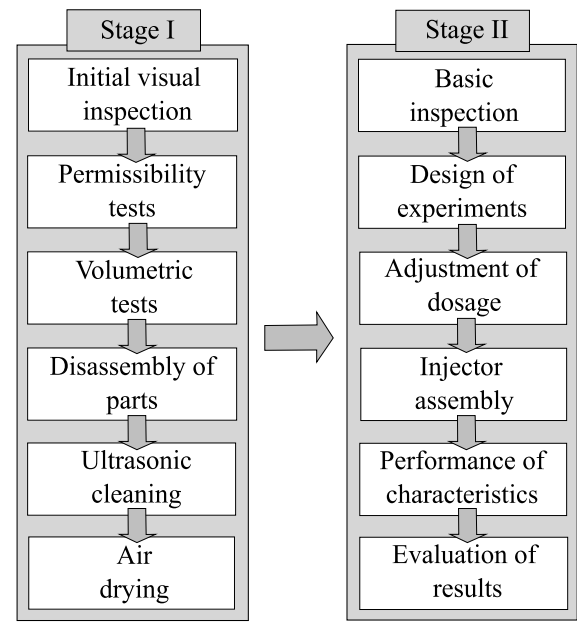

Fig. 2. Denso injector research methodology

The first of these began with the external examination of the injector, as well as the admission measurements, which included the following types of tests: electric - eRLC (Resistance, Inductance, Capacitance), LKT (Leak Test) and NOP (Nozzle Opening Pressure). In this phase, an auxiliary Bench CRU 2 Zapp diesel diagnostic test bench was used (Fig. 3). Volumetric tests iVM (Injector Volume Metering) were also conducted at the same station. They were carried out at various pressures and control times for doses of: full load VL (Ger. Vollast), emission EM (Ger. Emissionspunkt), idling LL (Ger. Leerlauf) and pilot VE (Ger. Voreinspritzung). Then the injector was disassembled into components, cleaned in ultrasonic washers and dried with compressed air.

In the second stage, the most important control and regulation parts were inspected using a laboratory microscope. Prior to assembly, the injector underwent a dose correction, which was based on the results of statistical analysis calculations. Idle characteristics were based on experimental data that was obtained on the STPiW-3 diagnostic test bench (Fig. 4).

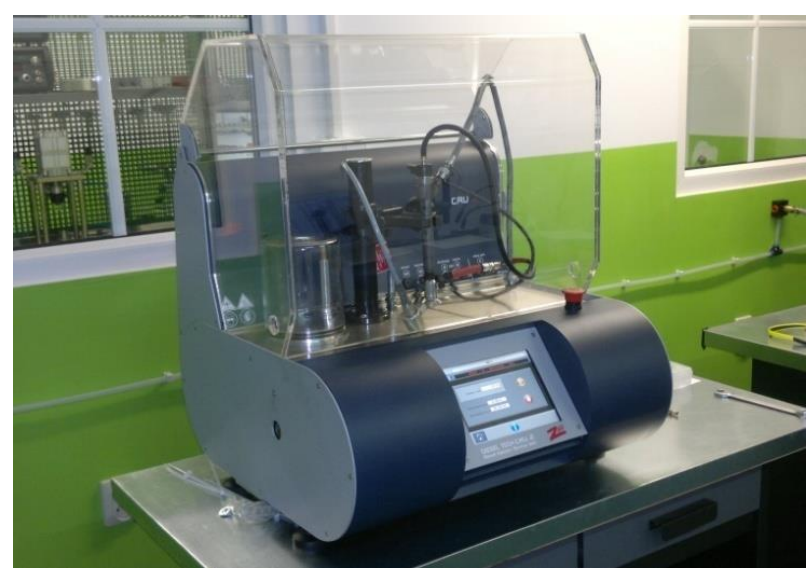

Fig. 3. Diesel Bench CRU 2 Zapp auxiliary diagnostic test bench

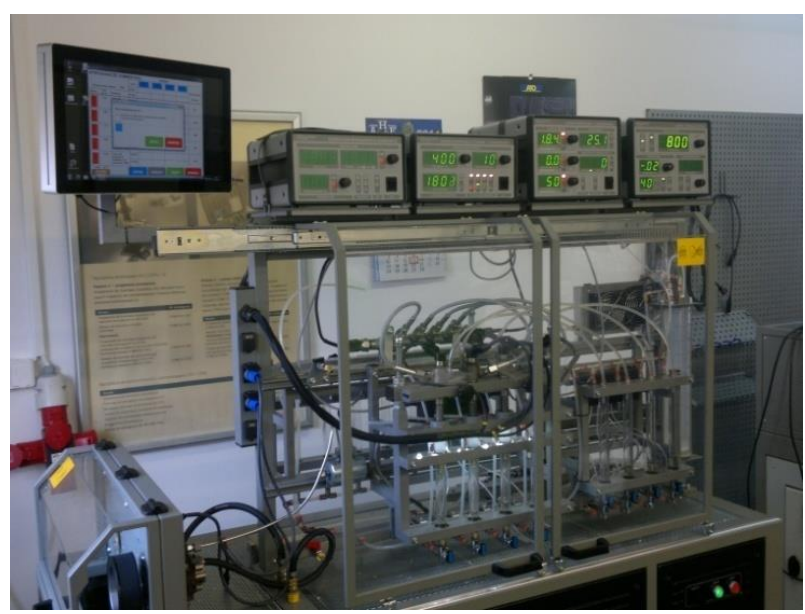

Fig. 4. Diesel Bench STPiW-3 main diagnostic test bench

\subsection{Preliminary tests results}

Electrical measurements excluded the failure of the electromagnet coil and its windings were not faulted to frame. The nozzle opening pressure was also positively evaluated and no leakage of test liquid was found in the leak test (Table 1).

Table 1. Approval tests results

\begin{tabular}{|c|c|c|}
\hline \multicolumn{2}{|c|}{ Test type } & Result \\
\hline \multirow{3}{*}{ Electric test eRLC } & Coil resistance, $R_{c}[\Omega]$ & 0.72 \\
\hline & Coil inductance, $L[\mu \mathrm{H}]$ & 180 \\
\hline & Winding faulted to frame & Not found \\
\hline \multicolumn{2}{|c|}{ Leak Test LKT $[\mathrm{MPa}]$} & 85.80 \\
\hline \multicolumn{2}{|c|}{ Nozzle Opening Pressure test NOP [MPa] } & 16.50 \\
\hline
\end{tabular}

Table 2. Volumetric tests results ,iVM”

\begin{tabular}{|c|c|c|c|}
\hline $\begin{array}{c}\text { Dose } \\
\text { type }\end{array}$ & $\begin{array}{c}\text { Injection } \\
\text { pressure, } \\
\mathrm{p}_{\text {inj }}[\mathrm{MPa}]\end{array}$ & $\begin{array}{c}\text { Duration of the } \\
\text { electrical pulse } \\
(\text { control }), \\
\mathrm{t}[\mu \mathrm{s}]\end{array}$ & $\begin{array}{c}\text { Nominal and actual } \\
\text { rate, } \\
\mathrm{D}\left[\mathrm{mm}^{3} / \text { injection }\right]\end{array}$ \\
\hline $\begin{array}{c}\text { Fullload } \\
\text { VL }\end{array}$ & 160 & 910 & $\begin{array}{c}57.99 \pm 8.41 \\
58.69\end{array}$ \\
\hline $\begin{array}{c}\text { Emission } \\
\text { EM }\end{array}$ & 80 & 720 & $\begin{array}{c}22.18 \pm 5.10 \\
21.13\end{array}$ \\
\hline $\begin{array}{c}\text { Idling } \\
\text { LL }\end{array}$ & 25 & 710 & $\begin{array}{c}4.73 \pm 2.23 \\
2.02\end{array}$ \\
\hline $\begin{array}{c}\text { Pilot } \\
\text { VE }\end{array}$ & 80 & 320 & $\begin{array}{c}2.23 \pm 1.48 \\
0.91\end{array}$ \\
\hline
\end{tabular}


Analysis of the results obtained in the volume tests showed that the injector is working properly. The exception was the too low idle dose value, which did not fall within the limits set by the manufacturer (Table 2).

\subsection{Design of experiments}

According to the design of experiments theory, one of the basic and most important tasks is to determine a set of quantities describing the object under study. Their number can be limited by thoughtful and careful allocation to particular groups [19]. This allows to obtain reliable results on the basis of a relatively small number of observations [2]. In this way, the labour consumption of conducted activities is reduced and the need to consider a comprehensive analysis of a given process is avoided [16].

In the present case, it was arbitrarily assumed that the idling period (dependent variable) is influenced by the following input quantities (independent variables) such as: time of control $t$, thickness of the needle $T_{n s}$ and the calibration $\mathrm{T}_{\mathrm{cs}}$ shim. It was also assumed that the interaction of disturbances and the constant factor is negligibly small, which means that they may not be included in further considerations (Fig. 5). All measurements were carried out in similar ambient conditions, at the minimum injection pressure $\left(\mathrm{p}_{\text {inj }}=25 \mathrm{MPa}\right)$.

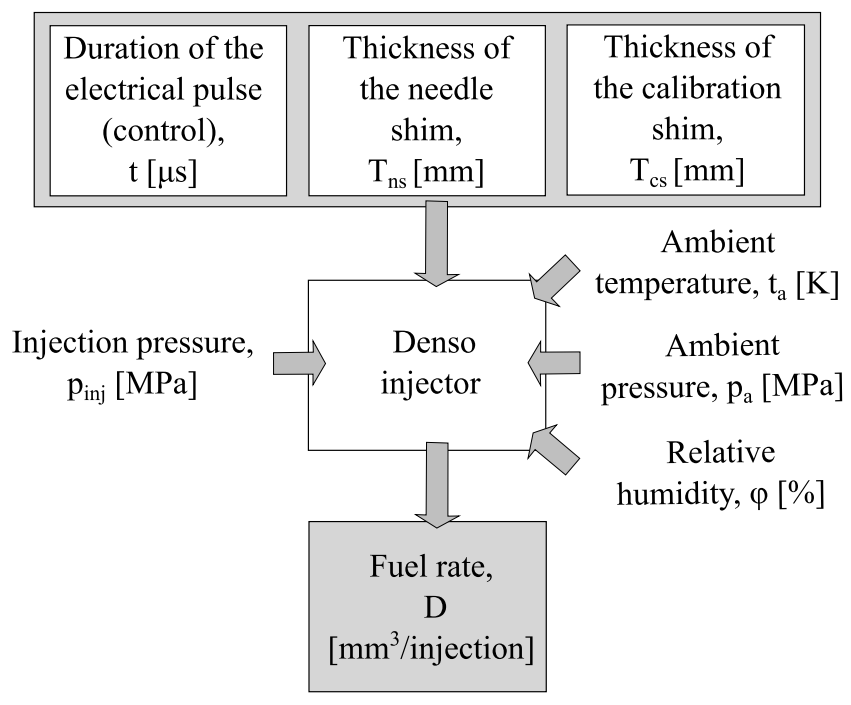

Fig. 5. Qualities defining the object under research

Conducting an experiment requires establishing the methodology that determines the selection of the correct plan [6]. It should guarantee a high rationality of research and enable obtaining the most reliable information about the object. In most cases, however, selective data, that is relevant to a specific problem, is sufficient [5]. For this reason, the determined plans are often chosen as they guarantee the ease of the mathematical preparation of the results [20]. At the same time, they retain the ability to create approximating functions reflecting the physical aspect of the experiment, while limiting the number of measurements required in their implementation [15]. In addition, the course of characteristics obtained on the STPiW-3 diagnostic test bench indicates that the injector's rate is described by a non-linear relationship [10]. For this reason, it was decided to use a trivalent fractional plan $3^{(\mathrm{k}-\mathrm{s})}$. This means that the input quantities in the number $\mathrm{k}$ assume values on three levels of variation $(-1,0,1)$, where $s$ is the degree of bisection [4].

Based on the assumptions made, which are related to the characteristics of the tested object, the selection plan 3/1/9 was created in the STATISTICA program. This record indicates that for 3 independent variables called generators $(\mathrm{X}, \mathrm{Y}, \mathrm{Z})$, the tests will be conducted in 1 block and 9 measuring points (Table 3 ).

Table 3. Trivalent fractional plan $3^{(\mathrm{k}-\mathrm{s})}$

\begin{tabular}{|c|c|c|c|}
\hline \multirow{2}{*}{$\begin{array}{c}\text { Point } \\
\text { number }\end{array}$} & \multicolumn{3}{|c|}{ Independent variables (generators) } \\
\cline { 2 - 4 } & $\mathrm{X}$ & $\mathrm{Y}$ & $\mathrm{Z}$ \\
\hline 1 & -1 & -1 & -1 \\
\hline 2 & -1 & 0 & 1 \\
\hline 3 & -1 & 1 & 0 \\
\hline 4 & 0 & -1 & 1 \\
\hline 5 & 0 & 0 & 0 \\
\hline 6 & 0 & 1 & -1 \\
\hline 7 & 1 & -1 & 0 \\
\hline 8 & 1 & 0 & -1 \\
\hline 9 & 1 & 1 & 1 \\
\hline
\end{tabular}

In the next step, the names of the input quantities and the corresponding numerical values were introduced (Table 4).

Table 4. Selection of input quantities in real space

\begin{tabular}{|c|c|c|c|c|}
\hline \multirow{2}{*}{ Generator } & \multirow{2}{*}{$\begin{array}{c}\text { Input quantity } \\
\text { (generator) }\end{array}$} & Lower & Central & Upper \\
\cline { 3 - 5 } $\mathrm{X}$ & $\begin{array}{c}\text { Duration of the electrical } \\
\text { pulse (control), } \\
\mathrm{t}[\mu \mathrm{s}]\end{array}$ & 200 & 700 & 1200 \\
\hline $\mathrm{Y}$ & $\begin{array}{c}\text { Thickness of the needle } \\
\text { shim, } \\
\mathrm{T}_{\mathrm{ns}}[\mathrm{mm}]\end{array}$ & 1.26 & 1.30 & $1.34 *$ \\
\hline $\mathrm{Z}$ & $\begin{array}{c}\text { Thickness of the } \\
\text { calibration shim, } \\
\mathrm{T}_{\mathrm{cs}}[\mathrm{mm}]\end{array}$ & $1.60 *$ & 1.64 & 1.68 \\
\hline
\end{tabular}

They were determined based on thickness measurements of shims using a standard digital micrometre. A selection of their new alternatives from well-defined selection groups was also made. In this aspect, the need to increase idle rate as well as the central position of the central plan value, which is the arithmetic mean of the lower and upper stellar points, was taken into account. The duration of electrical pulses, i.e. the control of the injector, was selected in the same way.

\section{Analysis results and discussion}

Table 5 presents the final plan of the experiment, the implementation of which can be carried out according to the variable order of individual assemblies. It should be noted that every replacement of the shims requires disassembly and re-assembly of the injector, which unnecessarily extends the time of its adjustment.

The statistical analysis also included squares of independent variables, which were introduced to estimate the 
Table 5. Trivalent fractional plan $3^{(k-s)}$ in the STATISTICA worksheet

\begin{tabular}{|c|c|c|c|c|c|c|c|}
\hline $\begin{array}{c}\text { Point } \\
\text { number }\end{array}$ & $\mathrm{t}$ & $\mathrm{T}_{\mathrm{ns}}$ & $\mathrm{T}_{\mathrm{cs}}$ & $\mathrm{t}^{2}$ & $\mathrm{~T}_{\mathrm{ns}}{ }^{2}$ & $\mathrm{~T}_{\mathrm{cs}}{ }^{2}$ & $\mathrm{D}$ \\
\hline 1 & 200 & 1.26 & 1.60 & 40000 & 1.5876 & 2.56 & 0.2 \\
\hline 2 & 200 & 1.30 & 1.68 & 40000 & 1.69 & 2.8224 & 0.1 \\
\hline 3 & 200 & 1.34 & 1.64 & 40000 & 1.7956 & 2.6896 & 0.1 \\
\hline 4 & 700 & 1.26 & 1.68 & 490000 & 1.5876 & 2.8224 & 3.2 \\
\hline 5 & 700 & 1.30 & 1.64 & 490000 & 1.69 & 2.6896 & 2.8 \\
\hline 6 & 700 & 1.34 & 1.60 & 490000 & 1.7956 & 2.56 & 1.9 \\
\hline 7 & 1200 & 1.26 & 1.64 & 1440000 & 1.5876 & 2.6896 & 7.1 \\
\hline 8 & 1200 & 1.30 & 1.60 & 1440000 & 1.69 & 2.56 & 6.2 \\
\hline 9 & 1200 & 1.34 & 1.68 & 1440000 & 1.7956 & 2.8224 & 5.9 \\
\hline
\end{tabular}

Table 6. Summary of multiple regression in the STATISTICA program

\begin{tabular}{|c|c|c|c|c|c|c|}
\hline \multirow{2}{*}{$\begin{array}{l}\text { Number of plan } \\
\text { points: } 9\end{array}$} & \multicolumn{6}{|c|}{$\begin{array}{l}\text { Correlation coefficient } \mathrm{R}=0.99947492 ; \text { Determination factor } \mathrm{R}^{2}=0.99895011 \text {; } \\
\text { Fisher-Snedecor test statistics } \mathrm{F}(5.3)=570.89 ; \text { Severity level } \mathrm{p}<0.00012 \\
\text { Estimation standard error: } 0.4657\end{array}$} \\
\hline & $\begin{array}{l}\text { Regression } \\
\text { predictor, } b^{*}\end{array}$ & $\begin{array}{c}\text { Standard error } \\
\text { with } b^{*}\end{array}$ & $\begin{array}{l}\text { Coefficient of } \\
\text { function, } b_{f}\end{array}$ & $\begin{array}{l}\text { Standard error } \\
\text { with } b_{f}\end{array}$ & $\begin{array}{l}\mathrm{b}_{\mathrm{f}} \text { quotient and its } \\
\text { standard error, } \mathrm{t}_{\mathrm{i}}(3)\end{array}$ & Severity level, p \\
\hline Free term & - & - & -692.7175556 & 174.1738353 & -3.97716 & 0.028431 \\
\hline $\mathrm{T}$ & 0.4252 & 0.092634 & 0.0027200 & 0.0005926 & 4.59010 & 0.019425 \\
\hline $\mathrm{T}_{\mathrm{ns}}$ & -0.1355 & 0.018707 & -10.8333333 & 1.4958791 & -7.24212 & 0.005430 \\
\hline $\mathrm{T}_{\mathrm{cs}}$ & 10.7290 & 2.657028 & 857.9166667 & 212.4622334 & 4.03797 & 0.027324 \\
\hline$t^{2}$ & 0.5661 & 0.092634 & 0.0000025 & 0.0000004 & 6.11104 & 0.008806 \\
\hline $\mathrm{T}_{\mathrm{cs}}{ }^{2}$ & -10.6824 & 2.657028 & -260.4166667 & 64.7734656 & -4.02042 & 0.027637 \\
\hline
\end{tabular}

coefficients of the approximating function to a non-linear form. In turn, the final column shows the final results of idle rate. In the case of multiple regression, the approximating function is obtained in such a way as to minimize the difference between the modelled value and the actual dependent variable for the input quantities.

The data summarized in Table 6 shows that for the considered case it will be at most a polynomial of the second degree, which, after taking into account the coefficients $b_{f}$, will take the form:

$$
\begin{aligned}
& \mathrm{D}=-692.7+2.7 \cdot 10^{-2} \cdot \mathrm{t}-10.8 \cdot \mathrm{T}_{\mathrm{ns}}+ \\
& +857.9 \cdot \mathrm{T}_{\mathrm{cs}}+2.5 \cdot 10^{-6} \cdot \mathrm{t}^{2}-260.4 \cdot \mathrm{T}_{\mathrm{cs}}{ }^{2}
\end{aligned}
$$

Analysis of computational data indicates that the generated parabolic model is very well suited to the actual results of the experiment. The qualitative measures are the coefficients of: multiple correlation $\mathrm{R}$ and determination $\mathrm{R}^{2}$, which are close to unity. The proper selection of the function is also confirmed by the high measure of the FisherSnedecor test and the corresponding level of significance ( $p$ $<0.00012$ ). In addition, the standard error of the estimation allows to conclude that the actual idling rate is slightly out of the projected value.

From the statistical point of view, almost all input quantities were significant and therefore they were included in the regression function. However, the lowest value of significance level was obtained for the thickness of the needle shim, which had a decisive influence on the injector rate. It follows that the idling adjustment should be limited only to reducing the preload of the needle spring. It should bring the expected results in a simplified research methodology. In turn, the replacement of the calibration shim is not recommended, because this way of regulation will have an indirect impact on the value of other rates and will force the need to check them in additional tests.

Figure 6 shows the characteristics of the tested injector. Thanks to the regulation, an increase in idle running rates was obtained, which were within the limits set by the manufacturer. It can also be seen that the waveforms of the approximation curves slightly deviate from the actual measurement results. For example, for the control time $t=200$ $\mu$ s and the simultaneous exchange of both shims, the estimated dose value was $0.7 \mathrm{~mm}^{3} /$ injection, while on the diagnostic test bench the value of $0.4 \mathrm{~mm}^{3} /$ injection was obtained (Table 7).

$$
\text { D }
$$

$\left[\mathrm{mm}^{3} /\right.$ injection]

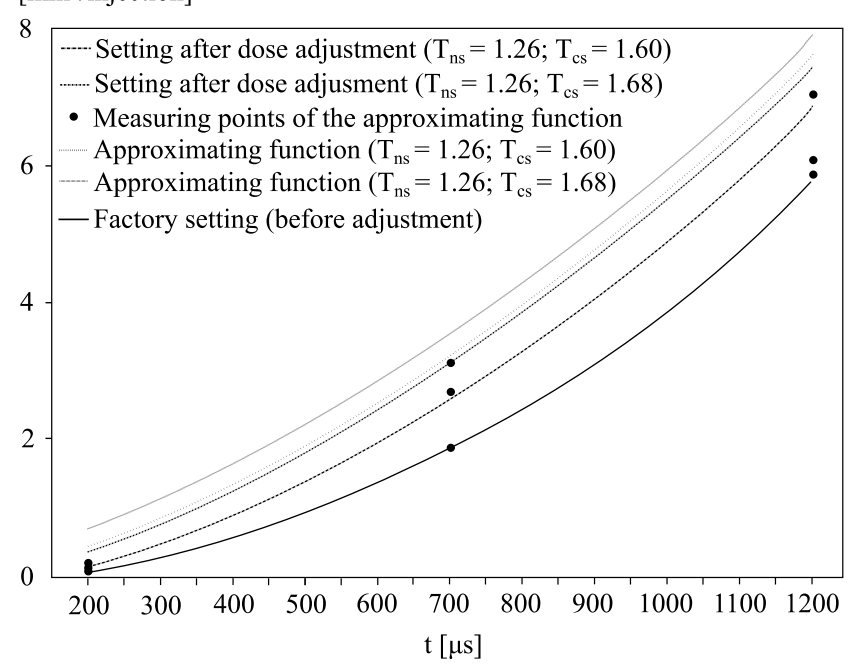

Fig. 6. Idle characteristics of the tested injector 
Table 7. Final results of tests and calculations

\begin{tabular}{|c|c|c|c|c|c|}
\hline $\begin{array}{c}\text { Duration of the } \\
\text { electrical pulse } \\
(\text { control), }\end{array}$ & $\begin{array}{c}\text { Factory } \\
\text { setting }\end{array}$ & \multicolumn{4}{|c|}{$\begin{array}{c}\text { Setting after } \\
\text { dose adjustment }\end{array}$} \\
\cline { 2 - 6 } & $\mathrm{T}_{\mathrm{ns}}=1.34$ & \multicolumn{2}{|c|}{$\mathrm{T}_{\mathrm{ns}}=1.26$} & \multicolumn{2}{|c|}{$\mathrm{T}_{\mathrm{ns}}=1.26$} \\
$\mathrm{~T}_{\mathrm{cs}}=1.60$ & $\mathrm{~T}_{\mathrm{cs}}=1.60$ & \multicolumn{2}{c|}{$\mathrm{T}_{\mathrm{cs}}=1.68$} \\
\hline 200 & 0.1 & 0.2 & $0.4^{*}$ & 0.4 & $0.7^{*}$ \\
\hline 450 & 0.8 & 1.2 & $1.7^{*}$ & 1.6 & $2.0^{*}$ \\
\hline 700 & 1.9 & 2.6 & $3.3^{*}$ & 3.2 & $3.6^{*}$ \\
\hline 950 & 3.6 & 4.5 & $5.3^{*}$ & 5.2 & $5.6^{*}$ \\
\hline 1200 & 5.7 & 6.9 & $7.6^{*}$ & 7.5 & $7.9^{*}$ \\
\hline * data estimated analytically & & & & \\
\hline
\end{tabular}

The data presented in the co-author's publication [18] shows that the repair of Denso electromagnetic injectors is characterized by very high efficiency with relatively small operational runs. In most cases, this process requires adjustment of idle dosage, which justifies the desirability of implementing the proposed calculation methodology in a wider scope. Nevertheless, over $200,000 \mathrm{~km}$ it is recommended to replace the precision pair with a new one (needle-spray nozzle), regardless of the type of failure identified. However, the growing number of failures of other regulation and control elements remains a problem. Their removal is not always possible, mainly due to limited access to original spare parts, which in turn is the manufacturer's conscious policy. As a result, the adoption of injectors coming from diesel engines with significant mileage is limited, because their repair becomes unreasonable or difficult to implement.

Typing the paper in this format is for the purpose of facilitating the editing process. The forms with text and fi- gures will be printed as delivered. Only in very few exceptional cases will other forms be accepted.

\section{Conclusions}

The design of experiments technique (DoE) allowed to determine the influence of input quantities on the object's response in a precise way. In this respect, the choice of the trivalent fractional plan should be assessed positively because the number of measurements carried out has been limited to the necessary minimum, while meeting the requirements for their implementation. An undoubted advantage of approximation is the possibility of good approximation with a low polynomial degree, which further simplifies the way of calculations. It has been shown that the implementation of factor experiments provides reliable quantitative data that can be used to support the repair process, as illustrated by the example of the Denso electromagnetic injector. It is worth noting that in the case of comprehensive research, all possible combinations of independent variables should be considered $\left(3^{3}=27\right.$ points $)$. Of course, such a solution provides more information, but it is much more labour-intensive and seems to be economically unjustified.

\section{Acknowledgements}

The repair of injectors was conducted on laboratory stands at VASCO Co. Ltd in Mierzyn near Szczecin, cooperating with the Department of Automotive Engineering of the West Pomeranian University of Technology (ZUT) in Szczecin.

\section{Nomenclature}

$\mathrm{b}^{*} \quad$ regression predictor

$b_{f} \quad$ coefficient of function

D rate

DoE design of experiments technique

EM emission dose (Ger. Emissionspunkt)

eRLC electric test (Resistance, Inductance, Capacitance)

F Fisher-Snedecor test statistics

HDI High pressure Direct Injection

iVM volumetric tests (Injector Volume Metering)

$\mathrm{k}$ number of input quantities

L coil inductance

LKT Leak Test

LL idling dose (Ger. Leerlauf)

NOP Nozzle Opening Pressure test

$\mathrm{p} \quad$ severity level

$\mathrm{p}_{\mathrm{a}} \quad$ ambient pressure $\mathrm{p}_{\text {inj }} \quad$ injection pressure

$\mathrm{R}$ correlation coefficient

$\mathrm{R}^{2} \quad$ determination factor

$\mathrm{R}_{\mathrm{c}} \quad$ coil resistance

$\mathrm{S} \quad$ degree of bisection

$\mathrm{t}$ duration of the electrical pulse (control)

$t_{a} \quad$ ambient temperature

$t_{i} \quad b_{f}$ quotient and its standard error

$\mathrm{T}_{\mathrm{cs}} \quad$ thickness of the calibration shim

$\mathrm{T}_{\mathrm{ns}} \quad$ thickness of the needle shim

VE pilot dose (Ger. Voreinspritzung)

VL full load dose (Ger. Vollast)

$\mathrm{X}$ independent variable (generator)

$\mathrm{Y}$ independent variable (generator)

$\mathrm{Z}$ independent variable (generator)

$\varphi \quad$ relative humidity

\section{Bibliography}

[1] ABRAMEK, K.F., STOECK, T., OSIPOWICZ T. Statistical evaluation of the corrosive wear of fuel injector elements used in common rail systems. Strojniški vestnik - Journal of Mechanical Engineering. 2015, 61(2), 91-98. DOI: 10.5545/sv-jme.2014.1687

[2] BARAD, M. Design of experiments (DOE) - A valuable multi-purpose methodology. Applied Mathematics. 2014, 5(14), 2120-2129. DOI: 10.4236/am.2014.514206
[3] BERNDT, S., SCHÜMANN, U., SADLOWSKI, T., BUCHHOLT, B. Development of a laboratory test for the deposit forming tendency of diesel fuels. ATZ offhighway worlwide. 2018, 11, 50-55. DOI: 10.1007/s41321-018-0006-2

[4] CAVAZZUTI, M. Optimization methods: from theory to design. scientific and technological aspects in mechanics. 2017, Springer-Verlag, Berlin Heidelberg. DOI: 10.1007/ 978-3-642-31187-1 
[5] DURAKOVIC, B. Design of experiments application, concepts, examples: state of the art. Periodicals of Engineering and Natural Sciences. 2017, 5(3), 421-439. DOI: 10.21533/pen.v5i3.145

[6] GARUD, S.S., KARIMI, I.A., KRAFT, M. Design of computer experiments: a review. Computers \& Chemical Engineering. 2017, 106, 71-95. DOI: 10.21533/pen.v5i3.145

[7] IGNACIUK, P., GIL, L. Damages to injectors in diesel engines. Advances in Science and Technology Research Journal. 2014, 8(21), 58-61. DOI: 10.12913/22998624.1091880

[8] JUŚCIŃSKI, S., PIEKARSKI, W., CHOMIK, Z. Analysis of injection systems types used in agricultural machines. Agricultural Engineering. 2017, 21(4), 37-46. DOI: 10.1515 /agriceng-2017-0034

[9] KARPIUK, W., BOR, W., SMOLEC, R. Possibilities of analysis of condition and repair of common-rail system injectors. Journal of KONES Powertrain and Transport. 2018, 23(4), 209-216. DOI: 10.5604/12314005.1217208

[10] KNEBA, Z., STRASZAK, P., JAKÓBCZYK, K. The effectiveness of fault detection in common rail injectors examination methods. Combustion Engines. 2017, 170(3), 49-56. DOI: 10.19206/ CE-2017-308

[11] MARČIČ, S., MARČIČ, M., PRAUNSEIS, Z. Mathematical model for the injector of a common rail fuel-injection system. Engineering. 2015, 7(6), 307-321. DOI: 10.4236/ eng.2015.76027

[12] OSIPOWICZ, T., ABRAMEK K.F. Diagnosing methods common rail fuel injectors. Combustion Engines. 2017, 168(1), 56-61. DOI: 10.19206/ CE-2017-109

[13] OSIPOWICZ, T., PRAJWOWSKI, K. Possibilities of research electromagnetic fuel injectors. Journal of KONES Powertrain and Transport. 2017, 24(2), 167-176. DOI: 10.5604/01.3001.0010

[14] ROUNTHWAITE, N.J., WILLIAM, R., McGIVERY, C. et al. A chemical and morphological study of diesel injector nozzle deposits - insights into their formation and growth mechanisms. SAE International Journal of Fuels and Lubricants. 2017, 10, 106-114. DOI: 10.4271/2017-01-0798

[15] SALVADOR, F.J., CARRERES, M., CRIALESI-ESPOSITO, M., PLAZAS, A.H. Determination of critical operating and geometrical parameters in diesel injectors through one dimensional modeling, design of experiments and an analysis of variance. Proceedings of the Institution of Mechanical Engineers, Part D: Journal of Automobile Engineering. 2017, 232, 1762-1781. DOI: 10.1177/0954407017735262

[16] SANGKI, P., YOUNGKUN, K., SEUNGCHUL, W., KIHYUNG, L. Optimization and calibration strategy using design of experiment for a diesel engine. Applied Thermal Engineering. 2017, 123, 917-928. DOI: 10.1016/j.applthermaleng.2017.05.171

[17] STĘPIEŃ, Z. A study of factors influencing the formation of harmful deposits in the diesel engine injectors. Eksploatacja i Niezawodność - Maintenance and Reliability. 2017, 19(3), 331-337. DOI: 10.17531/ein.2017.3.3

[18] STOECK, T., OSIPOWICZ, T., ABRAMEK, K.F. Methodology for the repair of Denso common rail solenoid injectors. Eksploatacja i Niezawodność - Maintenance and Reliability. 2014, 16(2), 270-275.

[19] TAGHAVIFAR H., JAFARMADAR S., TAGHAVIFAR H., NAVID A. Application of DoE evaluation to introduce the optimum injection strategy-chamber geometry of diesel engine using surrogate epsilon-SVR. Applied Thermal Engineering. 2016, 106, 56-66. DOI: 10.1016/j.applthermaleng. 2016.05.194

[20] YIN, Y., ZHOU, J. Minimax design criterion for fractional factorial designs. Annals of the Institute of Statistical Mathematics. 2015, 67(4), 673-685. DOI: 10.1007/s10463-0140470-0

[21] YONG, Z., BO, Q., DAQING, G., GUOYOU, M. Optimization of injector nozzle in high pressure common rail injection system. Journal of Mechanical Engineering Research and Developments. 2018, 41(1), 27-37. DOI: 10.7508/ jmerd.2018.01.004

Tomasz Stoeck, DEng. - Faculty of Mechanical Engineering and Mechatronics, West Pomeranian University of Technology in Szczecin, Poland. e-mail: tstoeck@wp.pl 